\title{
Absence of history of oral cleft in first-degree relatives of patients
}

\section{with prostate cancer}

\author{
Cláudia de Alvarenga Diniz Fonseca, ${ }^{1,2}$ Daniella Reis Barbosa Martelli, ${ }^{3}$ lanná Luana Freitas Almeida, ${ }^{2}$ Galeno Hassen Sales, ${ }^{2}$ Rodrigo Soares \\ de Andrade, ${ }^{4}$ Verônica Oliveira Dias, ${ }^{3}$ Letízia Monteiro de Barros, ${ }^{5}$ Hercílio Martelli Júnior ${ }^{1,3,5}$
}

${ }^{1}$ Health Science Program, State University of Montes Claros, Unimontes, Minas Gerais, Brazil.

${ }^{2}$ Medicine School, State University of Montes Claros, Montes Claros, Minas Gerais, Brazil.

${ }^{3}$ Dental School, State University of Montes Claros, Montes Claros, Minas Gerais, Brazil.

${ }^{4}$ Department of Oral Pathology, Dental School, University of Campinas, UNICAMP, Piracicaba, São Paulo State, Brazil.

${ }^{5}$ Center for Rehabilitation of Craniofacial Anomalies, University of José Rosario Vellano, Alfenas, Minas Gerais, Brazil.

\section{Abstract}

Objective: To evaluate the occurrence of nonsyndromic cleft lip and/or palate (NSCL/P) in families of patients with prostate cancer (PC). Study design: We conducted a case-control study involving a total of 748 individuals, 280 of which had PC, and 468 were free-cancer healthy individuals. The patients answered a questionnaire with basic demographic information and family history of NSCL/P in firstdegree relatives. The information collected was stored in a database and analyzed by using the statistical program SPSS ${ }^{\circ} 24.0$ for Windows (Chicago, IL, USA). In order to determine the association with NSCL/P, chi-square and Fisher's exact test and odds ratio (OR) with its $95 \%$ confidence interval $(95 \% \mathrm{Cl})$ for risk magnitude assessment. Values with $p<0.05$ were considered statistically significant. Results: Of total patients with PC, 2 had a positive history of NSCL/P. In the control group, 7 patients reported family history of NSCL/P (1df chi-square, $p=0.34$; Fisher's exact test, $p=0.49$ ). The average age of the cases diagnosed with $P C$ was $71.35 \pm 7.70$ years, and control group was $64.42 \pm 9.67$ years.

Conclusion: Despite the limited population, the frequency of NSCL/P was not significantly increased in the first-degree relatives of patients with PC. Studies with larger samples and molecular analyses are needed to better understand the possible relationships in the etiology of cancer and NSCL/P.
Citation: Fonseca CAD, et al. (2019) Absence of history of oral cleft in first-degree relatives of patients with prostate cancer. Dentistry 3000. 1:a001 doi: $10.5195 / \mathrm{d} 3000.2019 .88$ Received: November 3, 2018 Accepted: April 4, 2019 Published: July 25, 2019

Copyright: (C2019 Fonseca CAD, et al. This is an open access article licensed under a Creative Commons Attribution Work 4.0 United States License. Email:cdadiniz@gmail.com

\section{Introduction}

Prostate cancer (PC) is one of the most frequent cancers in men, and it is estimated to affect $1,618,000$ men, and led to 366,000 deaths globally in 2015 (1). An American estimate published in 2017 showed that prostate, lung and bronchus, and colorectal cancers account for $42 \%$ of all cases in men, with prostate cancer alone accounting for almost 1 in 5 new diagnoses. For women, the 3 most common cancers are breast, lung, and colorectum, which collectively represent one-half of all cases; breast cancer alone accounts for $30 \%$ all new cancer diagnoses in women (2). In Brazil, 68,220 new cases of PC are estimated for each year in 2018-2019. These values correspond to an estimated risk of 66.12 new cases for every 100 thousand men. PC is the most incident among men in all regions in Brazil (3). 
Nonsyndromic cleft lip and/or cleft palate [(NSCL/P); OMIM \#119530] is the most common craniofacial birth defect in humans with a global prevalence ranging from 1:500 to $1: 2,500$ live births (4). In Brazil, the prevalence varies from 0.36 to 1.54 per 1,000 live births $(5,6)$. About $70 \%$ of the cases occur as a nonsyndromic form (NSCL/P), and the remaining 30\% are associated with Mendelian disorders or chromosomal, teratogenic and sporadic conditions (7). Although there has been marked progress in identifying environmental and genetic risk factors associated with $\mathrm{NSCL} / \mathrm{P}$, its etiology in most of the cases remains unclear $(4,8)$. Based on epidemiological features and embryologic timing, NSCL/P are traditionally divided in nonsyndromic cleft lip (NSCL), nonsyndromic cleft lip and palate (NSCLP) and nonsyndromic cleft palate (NSCP) (9).

It has been proposed that cancer and congenital malformations such as NSCL/P may occasionally have a common etiology. The underlying concept is that genes acting in normal development may also have an important role in malignancies (9). A study published in 2015 showed that having an oral cleft increases the risk for self-reported history of cancer in family members, and genetic variants in $D L X 1$ and MMP3 are associated with oral cleft regardless of the history of cancer (10). Over the past years, epidemiological studies have assessed the relationship between cancer and NSCL/P in different populations [Texas, USA (11), Southeast Asian (12), Denmark (13), Pittsburgh, USA (14), Latvia (15), India (16), The Netherlands (17), Danish (18), Turkey (19), Brazil (20), France (21), Brazil $(8,22)$, Poland (23), Pakistan (24), Brazil (25)], and the results are controversial.

The finding of an increased risk of $\mathrm{NSCL} / \mathrm{P}$ in families with cancer case would strengthen the hypothesis that common genetic factors may play a role in both situations. Thus, the aim of this study was to evaluate the frequency of NSCL/P in first-degree families of patients with $\mathrm{PC}$.

\section{Materials and Methods}

We conducted a case-control study. All patients with PC (case group; $\mathrm{n}=280$ ) attended in a reference service in oncology, in Minas Gerais State, Brazil, from June 2016 to December 2017 were evaluated. The following inclusion criteria were applied: having a diagnosis of $P C$ and to be undergoing treatment at the institution. The sampling was performed by convenience, and the groups were matched concerning age. The control group included 468 free-cancer healthy individuals randomly obtained at the general clinics and at the University Hospital. Study participants signed an informed consent and answered in person a structured questionnaire with basic demographic information that included the following data on self-reported for analysis: age, skin color, history of NSCL/P in first-degree relatives (mother, father, siblings and children) through self-identification by illustrative figures.

The information collected was stored in a database and analyzed by using the statistical program SPSS $^{\oplus}$ version 24.0 (Statistical Package for Social Sciences for Windows, Inc., Chicago, IL,USA). A descriptive and comparative statistical analysis was initially carried out with baseline characteristics among groups such as age, skin color, and history of NSCL/P (first degree relatives). A binary logistic regression was used for statistical analysis of the color categorical variable. MannWhitney's test for unpaired samples was performed to compare the age averages between the groups. In order to determine the association with $\mathrm{NSCL} / \mathrm{P}$, chi-square and Fisher's exact test and odds ratio (OR) with its $95 \%$ confidence interval (95\% $\mathrm{Cl})$ for risk magnitude assessment. Values with $p<0.05$ were considered statistically significant.

All subjects enrolled in this study lived in the same geographical area (Northern of the state of Minas Gerais, Brazil). Thus, controls group presented demographic ethnic and sociocultural characteristics similar to the PC group. Written informed consents were obtained, and the study was carried out with approval of the University Human Research Ethics Committee (\# 436.750). 


\section{Results}

The average age of the cases diagnosed with PC was 71.35 \pm 7.70 years, and control group was $64.42 \pm 9.67$ years $(p=0,000)$. The majority of the participants de clared themselves to be brown or black, both in PC and in freecancer healthy individuals groups (79.3\%, 72.6\%, respectively). Black subjects were 1.81 times more likely to have prostate cancer than white subjects, with a statistically significant difference ( $p=0.02$; OR:1.81; $\mathrm{Cl}: 1.17-2.80)$. Nine out of 748 study participants had a positive history of NSCL/P. Among 280 patients with PC, 2 had a identify approximately 4 or 5 cases of NSCL/P in relatives of patient with PC $(280 \times 16 / 1,000)$ and 7 or 8 cases among relatives of the controls $(468 \times 16 / 1,000)$. Thus, in this study NSCL/P frequency was not significantly increased in firstdegree relatives of patients with PC.

\section{Discussion}

Cancer is a multifactorial disease in which both genetic and environmental factors play a significant role. Preventive plans for decreasing cancer incidence include both the removal of environmental agents known to be carcinogens and the

Table 1. Frequency of prostate cancer (PC) patients with positive and negative history of nonsyndromic cleft lip and/or palate (NSCL/P) in first-degree relatives

\begin{tabular}{|c|c|c|c|c|c|}
\hline $\begin{array}{c}\text { Family history } \\
\text { of NSCL/P }\end{array}$ & $\begin{array}{c}\text { PC Group } \\
\text { n (\%) }\end{array}$ & $\begin{array}{l}\text { Control } \\
\text { Group } \\
\text { n (\%) }\end{array}$ & OR & Cl 95\% & $\begin{array}{c}p- \\
\text { value }\end{array}$ \\
\hline Yes & $2(0.7)$ & $7(1.5)$ & \multirow{2}{*}{2.11} & \multirow{2}{*}{$0.435-10.232$} & $0.34^{a}$ \\
\hline No & 278 (99.3) & 461 (98.5) & & & $0.49^{b}$ \\
\hline
\end{tabular}

${ }^{a}$ Chi-square test; ${ }^{b}$ Fisher's exact test

positive family history of NSCL/P. In the control group, 7 patient reported family history of NSCL/P (1df chi-square, $p=0.34$; Fisher's exact test, $p=0.49$ ) (Table 1 ).

With this sample size, the frequency of NSCL/P as $1 / 1,000$ live births and the average of the Brazilian family size of 16 individuals (8), we would expect to both sexes combined and the second most common cancer in men. In 2012, estimates showed approximately 1.1 million new cases of PC, accounting for $15 \%$ of the cancers diagnosed in men (26). Regarding mortality, global estimates of the Globocan Project, the International Agency for Research on Cancer (IARC) of the World Health Organization (WHO), pointed 307,000 deaths in 2012; and the overall mortality rate for the same year was $7.8 / 100,000$, representing $6.6 \%$ of the total male cancer mortality (26).

In this research the frequency of NSCL/P was not significantly increased in first-degree relatives of patients with PC. Dietz et al. (2012) analyzed the risk of breast cancer in families with NSCL/P, but they were unable to confirm a general increase of breast cancer risk among female subjects in families with clefts (18). Martelli et al. (2014) analyzed the risk of NSCL/P in families of women with breast cancer, but they were unable to confirm a general increase in the risk of NSCL/P among families of women with breast cancer (8).

On the other hand, Menezes et al. (2009) showed a family history of cancer (colon, brain, leukemia, breast, prostate, skin, lung and liver) more often in relatives of NSCL/P compared to the control group (14). Taioli et al. (2010) evaluated the presence of NSCL/P in family members of cancer patients. Among cancer survivors with a family member with $\mathrm{NSCL} / \mathrm{P}$, there was an apparent 
excess of testicular cancer and melanoma in comparison with the cancer survivors with no family history of NSCL/P (27). Jindal and Vieira (2012) showed a correlation between acute lymphoblastic leukemia and NSCL/P in a population from India. The occurrence of NSCL/P was more frequent in families with acute lymphoblastic leukemia than in families without the diagnosis of this pediatric cancer (16).

Possible mechanisms at the basis of an association between NSCL/P and cancer are shared genetic factors. The first study to characterize possible pleiotropic loci for NSCL/P and cancer using large genomic datasets was published in 2016. Suggestive evidence for a common genetic background was found for NSCL/P and follicular lymphoma at 6p21.33, and for NSCL/P and squamous cell carcinoma of the skin in 20q12 (28).

The hypothesized association between cancer and NSCL/P could be attributed to factors that have been suspected to be at the basis of these associations which are polymorphic variants in genes involved in cell-to-cell adhesion and cell motility $(17,21)$. Study involving mutation analysis in PC cells pointed inactivating homozygous mutations in the SYNJ2 and CLPTM1 genes. Disruption of nonsense-mediated mRNA decay (NMD) pathway suggested that both genes carried nonsense mutations in LNCaP cells. The sequence analysis identifies homozygous deletions within mononucleotide repeats in the coding regions of both of these genes (29). Recently, we studied the relationship between breast and gastric cancer and NSCL/P. Our results suggest that polymorphic variants in AXIN2 and $C D H 1$ may be associated with NSCL/P and reinforce the putative link between cancer and oral clefts (9). The finding of an increased risk of NSCL/P in families of cancer patients would strengthen the hypothesis that common genetic and epigenetic mechanisms are playing a role in both conditions.

Some limitations should be considered in the present study, including the use of self-reported information and the memory bias associated with the study design (control case), reason to choose the history of NSCL/P only in first degree relatives. The lack of ethnicity pairing may also be considered a potential limitation when taking into account the higher incidence of prostate cancer in black men worldwide. However, some studies consider the risk of prostate cancer to be similar among black and white men in Brazil (30).

Our results are in accordance with a systematic review with metaanalysis which has demonstrated a higher prevalence of prostate cancer in black men compared to Brazilian white or brown men (31). We believe that the complex ethnic mix in the Brazilian population, which includes the contribution of European, African and Native American ancestry, makes this kind of pairing difficult. A study on the genomic ancestry of individuals from different geographic regions of Brazil reported considerable variability in the ancestry of color categories in different regions, most of which are manifested in brown and black individuals. For individuals classified as black, they observed considerable but highly discrepant levels of European descents, ranging from $29.3 \%$ to $53.9 \%$, depending on the region (32).

The reduced number of NSCL/P history among first-degree relatives in both groups did not allow a comparative analysis of the mean between them. Finally, the small size and type of sample involving individuals from hospitals may pose a risk of not representing the general population.

\section{Conclusion}

Our results conclude that the frequency of NSCL/P was not significantly increased in the firstdegree relatives of patients with PC. Studies with larger samples and molecular analyses are needed to better understand the possible relationships in the etiology of cancer and NSCL/P.

\section{Acknowledgments}

This work was supported by grants from The State of Minas Gerais Research Foundation-FAPEMIG, Minas Gerais, Brazil and the National Council for Scientific and Technological Development-CNPq, Brasília, Brazil. 


\section{References}

1. Fitzmaurice C, Allen C, Barber R. Global, regional, and national cancer incidence, mortality, years of life lost, years lived with disability, and disability-adjusted life-years for 32 cancer groups, 1990 to 2015: a systematic analysis for the global burden of disease study. JAMA Oncol. 2017; (3):524-548. PMID: 27918777

2. Siegel RL, Miller KD, Jemal A. Cancer Statistics, 2017. CA Cancer J Clin [Internet]. 2017;67(1):7-30. PMID: 28055103

\section{INCA. The National Cancer} Institute. Cancer statistic. Brazil:INCA, 2017.

4. Dixon MJ, Marazita ML, Beaty TH, Murray JC. Cleft lip and palate: understanding genetic and environmental influences. Nat Rev Genet. 2011;(12):167-178. PMID: 21331089

5. Martelli-Junior $\mathrm{H}$, Porto LV, Martelli DR, Bonan PR, Freitas AB, Coletta RD. Prevalence of nonsyndromic oral clefts in a reference hospital in the state of Minas Gerais, Brazil, between 2000-2005. Braz Oral Res.

2007;(21):314-317. PMID: 18060257

6. Rodrigues K, Sena MFD, Roncalli $A G$, Ferreira MAF. Prevalence of orofacial clefts and social factors in Brazil. Braz Oral Res. 2009;(23):38-42. PMID: 19488470

7. Meng L, Bian Z, Torensma R, Von DenHoff JW. Biological mechanisms in palatogenesis and cleft palate. J Dent Res. 2009;(88):22-33. PMID: 19131313

8. Martelli DR, Vieira AR, Fonseca AT, Coletta RD, Soares PB, Martelli-Júnior $H$. Risk of nonsyndromic cleft lip and palate in relatives of women with breast cancer. Am J MedGenet. 2014;(164):270-271. PMID: 24259269

9. Machado RA, de Freitas EM, de Aquino SN, Martelli DR, Swerts MS, Reis SR, et al. Clinical relevance of breast and gastric cancer-associated polymorphisms as potential susceptibility markers for oral clefts in the Brazilian population. BMC Med Genetics. 2017;(5):18-39. PMID: 28376813

10. Sabóia TM, Reis MF, Martins ÂMC, Romanos HF, Tannure PN, Granjeiro JM, et al. DLX1 and MMP3 contribute to oral clefts with and without positive family history of cancer. Arch Oral Biol. 2015;60(2):223-228. PMID: 25463899

11. Steinwachs EF, Amos C, Johnston D, Mulliken J, Stal S, Hecht JT. Nonsyndromic cleft lip and palate is not associated with cancer or other birth defects. Am J Med Genet. 2000;(90):17-24. PMID: 10602112

12. Nishi M, Miyake $H$, Takeda $T$, Hatae Y. Congenital malformations and childhood cancer. Med Pediatr Oncol. 2000;(34):250-254. PMID: 10742060

13. Zhu JL, Basso O, Hasle H, Winther JF, Olsen JH, Olsen J. Do parents of children with congenital malformations have a higher cancer risk? A nationwide study in Denmark. Br J Cancer. 2002;(87):524-528. PMID: 12189550

14. Menezes R, Marazita ML, Goldstein McHenry T, Cooper ME, Bardi K, Brandon C, et al. AXIS inhibition protein 2 , orofacial clefts and a family history of cancer. J Am Dent Assoc. 2009;(140):80-84. PMID: 19119171
15. Vieira AR, Khaliq S, Lace B. Risk of cancer in relatives of children born with isolated cleft lip and palate. Am J Med Genet A. 2012;(158):1503-1504. PMID: 22585460

16. Jindal A, Vieira AR. Family history of cleft lip and palate in subjects diagnosed with leukemia. Am J Med Genet A. 2012;(158):678-679. PMID: 22302642

17. Kluijt I, Sijmons RH, Hoogerbrugge $\mathrm{N}$, Plukker JT, De Jong D, Van Krieken $\mathrm{JH}$, et al. Familial gastric cancer: guidelines for diagnosis, treatment and periodic surveillance. Fam Cancer. 2012;(11):363-369. PMID: 22388873

18. Dietz $\underline{A}$, Pedersen DA, Jacobsen $\underline{R}$, Wehby GL, Murray JC, Christensen K. Risk of breast cancer in families with cleft lip and palate. Ann Epidemiol. 2012;(22):37-42. PMID: 22037380

19. Yildirim M, Seymen F, Deeley K, Cooper ME, Vieira AR. Defining predictors of cleft lip and palate risk. J Dent Res. 2012;(91):556-561. PMID: 22037380

20. Lima LS, Silvério Mde O, Swerts MS, Aquino SN, Martelli DR, MartelliJúnior $\mathrm{H}$. Frequency of cancer in firstdegree relatives of patients with cleft lip and/or palate in the Brazilian population. Braz Dent J.

2013;(24):200-203. PMID: 23969906

21. Benusiglio PR, Caron O, Consolino E, Duvillard P, Coulet F, Blayau M, et al. Cleft lip, cleft palate, hereditary diffuse gastric cancer and germline mutations in $\mathrm{CDH} 1$. Int J Cancer. 2013;(132): 2466-2470. PMID: 23124477

22. Gonçalves E, Martelli DR, Coletta $R D$, Vieira AR, Caldeira AP, MartelliJúnior $\mathrm{H}$. Risk of leukemia in first degree relatives of patients with 
nonsyndromic cleft lip and palate.

Braz Oral Res. 2014;(28):1-3. PMID: 25337933

23. Hozyasz KK, Mostowska A, Wójcicki P, Lasota A, Offert B, Balcerek $A$, et al. Nucleotide variants of the cancer predisposing gene $\mathrm{CDH} 1$ and the risk of non-syndromic cleft lip with or without cleft palate. Fam Cancer. 2014;(13):415-421. PMID: 24838934

24. Bui AH, Ayub A, Ahmed MK, Taioli E, Taub PJ. Association Between Cleft Lip and/or Cleft Palate and Family History of Cancer: A Case-Control Study. Ann Plast Surg. 2018;(80):178181. PMID: 29389703

25. Cardoso EF, Martelli DR, Machado RA, Coletta RD, de Souza JD, Barbosa FT et al. Nonsyndromic cleft lip and palate, gastric cancer and tooth agenesis. Med Oral Patol Oral Cir Bucal. 2018;(23):44-48. PMID: 29274157

26. Ferlay J, Soerjomataram I, Dikshit R, Eser S, Mathers C, Rebelo M, et al. Cancer incidence and mortality worldwide: sources, methods and major patterns in GLOBOCAN 2012. Int J Cancer. 2015;(136):359-386.

PMID: 25220842

27. Taioli E, Ragin C, Robertson L, Linkov F, Thurman N E, Vieira A R. Cleft Lip and Palate in Family Members of Cancer Survivors. Cancer Invest. 2010; 28(9): 958-962. PMID: 20569073

28. Dunkhase E, Ludwig KU, Knapp M, Skibola CF, Figueiredo JC, Julie F, et al. Nonsyndromic cleft lip with or without cleft palate and cancer: Evaluation of a possible common genetic background through the analysis of GWAS data. Genomics Data. 2016;(10):22-9. PMID:

27630819
29. Rossi MR, Hawthorn L, Platt J, Burkhardt T, Cowell JK, lonov Y. Identification of inactivating mutations in the JAK1, SYNJ2, and CLPTM1 genes in prostate cancer cells using inhibition of nonsense-mediated decay and microarray analysis. Cancer Genet Cytogenet. 2005;161(2):97103. PMID: 16102578

30. Barros MS, Silva VR, Santos GB, Hughes $A$, Silveira MA. Prevalence of prostate adenocarcinoma according to race in an university hospital. Int Braz J Urol. 2003;(29): 306-11. PMID: 15745553

31. Romero FR, Romero AW, de Almeida RMS, Filho RT. The prevalence of prostate cancer in Brazil is higher in Black men than in White men: Systematic review and metaanalysis. Int Braz J Urol. 2012;38(4):440-7. PMID: 22951172

32. Pena SDJ, Di Pietro G, FuchshuberMoraes M, Genro JP, Hutz MH, Kehdy FSG et al. The genomic ancestry of individuals from different geographical regions of Brazil is more uniform than expected. PloS One. 2011; 6(2). PMCID: PMC3040205 